\title{
Osthole enhances TRAIL-mediated apoptosis through downregulation of c-FLIP expression in renal carcinoma Caki cells
}

\author{
KYOUNG-JIN MIN, MIN AE HAN, SHIN KIM, JONG-WOOK PARK and TAEG KYU KWON
}

Department of Immunology, School of Medicine, Keimyung University, Dalseo-Gu, Daegu 704-701, Republic of Korea

Received November 29, 2016; Accepted December 28, 2016

DOI: $10.3892 / o r .2017 .5490$

\begin{abstract}
Osthole, an active constituent isolated from the fruit of Cnidium monnieri (L.) Cusson, has been shown to induce various beneficial biochemical effects such as anti-inflammatory and antitumor. In the present study, we examined whether osthole could sensitize TNF-related apoptosis-inducing ligand (TRAIL)-induced apoptosis in human renal carcinoma Caki cells. We found that osthole and TRAIL alone, had no effect on apoptosis, but combined treatment with osthole and TRAIL markedly induced apoptosis in Caki (renal carcinoma), U251MG (glioma) and MDA-MB-231 (breast carcinoma) cells. In contrast, combined treatment with osthole and TRAIL did not induce apoptosis in normal human skin fibroblast cells. Osthole induced downregulation of cellular FLICE-like inhibitory protein (c-FLIP) expression, and overexpression of c-FLIP markedly blocked apoptosis induced by the combined treatment with osthole and TRAIL. In addition, osthole markedly reduced mitochondrial membrane potential levels, and increased cytosolic cytochrome $c$ release in combined treatment with osthole and TRAIL. Therefore, these data suggest that osthole may be an efficient TRAIL sensitizer.
\end{abstract}

\section{Introduction}

Osthole [7-methoxy-8-(3-methyl-2-butenyl)-2H-1-benzopyran-2-one] is one of effective compounds found in Cnidium monnieri. It has been shown to exert multiple functions including anti-inflammatory and antiproliferative effects (1-4).

Correspondence to: Professor Taeg Kyu Kwon, Department of Immunology, School of Medicine, Keimyung University, 2800 Dalgubeoldaero, Dalseo-Gu, Daegu 704-701, Republic of Korea

E-mail:kwontk@dsmc.or.kr

Abbreviations: TRAIL, tumor necrosis factor-related apoptosisinducing ligand; ROS, reactive oxygen species; DISC, death-inducing signaling complex; HSF, human skin fibroblast; DR, death receptor; FADD, FAS-associated protein death domain; MMP, mitochondrial membrane potential

Key words: osthole, TRAIL, c-FLIP, caspase, MMP
Recently, it has been reported that osthole induces apoptosis in hepatocellular carcinoma cells through inhibition of nuclear factor- $\kappa \mathrm{B}(\mathrm{NF}-\kappa \mathrm{B})$ activity and modulation of apoptosisrelated genes (2). Osthole was found to suppress proliferation of ovarian cancer cells by promoting G2/M arrest and to induce apoptosis (3). In addition, osthole inhibited epithelial to mesenchymal transition (EMT)-mediated metastasis through reduction of Snail-DNA-binding activity and induction of E-cadherin expression (5), and suppressed migration and invasion of lung cancer cells via inhibition of metalloproteinase (MMP)-2 and -9 levels (6). However, the anticancer effect of osthole requires further elucidation.

Tumor necrosis factor (TNF)-related apoptosis-inducing ligand (TRAIL) was identified to be a member of the TNF ligand family. TRAIL has been shown to be effective in inducing apoptosis through death receptor (DR)4 and/or DR5 in a variety of tumor cells, but not normal cells $(7,8)$. Upon the binding of TRAIL to DR, DR recruits FAS-associated protein death domain (FADD) and caspase-8, resulting in the formation of the death-inducing signal complex (DISC) (9). However, the downregulation of DR expression and the upregulation of anti-apoptotic proteins (c-FLIP, Bcl-2, Bcl-xL and IAPs) cause resistance to TRAIL-induced apoptosis in many cancer cell types (10-14). Therefore, identification of TRAIL sensitizers is required to overcome TRAIL resistance.

In the present study, we showed that osthole enhances TRAIL-induced apoptotic cell death through downregulation of c-FLIP expression. Osthole may be an efficient apoptosis sensitizer that can overcome chemoresistance against TRAIL.

\section{Materials and methods}

Cell cultures and materials. Human renal carcinoma (Caki), human glioma (U251MG) and human breast cancer (MDAMB-231) cells were obtained from the American Type Culture Collection (ATCC; Manassas, VA, USA). The normal human skin fibroblast (HSF) cells were purchased from the Korea Cell Line Bank (Seoul, Korea). The culture medium used throughout these experiments was Dulbecco's modified Eagle's medium (DMEM) containing 10\% fetal bovine serum (FBS), $20 \mathrm{mM}$ HEPES buffer (all from Welgene, Daegu, Korea) and $100 \mu \mathrm{g} / \mathrm{ml}$ gentamicin (Gibco, Grand Island, NY, USA). Osthole was purchased from Abcam (Cambridge, MA, USA). Recombinant human TRAIL and z-VAD-fmk was purchased 
from R\&D Systems (Minneapolis, MN, USA). Anti-Mcl-1, anti-Bcl-2, anti-cIAP2, anti-CHOP and anti-ATF4 antibodies were purchased from Santa Cruz Biotechnology (Santa Cruz, CA, USA). Anti-MnSOD was purchased from Millipore Corp. (Billerica, MA, USA). Anti-caspase-3 and anti-Grp78 antibodies were purchased from ENZO (Ann Arbor, MI, USA). Anti-cytochrome $c$ and anti-XIAP antibodies were purchased from BD Biosciences (San Jose, CA, USA). Anti-c-FLIP antibody was obtained from Alexis Corporation (San Diego, CA, USA). Anti-PARP, anti-cleaved caspase-3, and anti-DR5 antibodies were purchased from Cell Signaling Technology (Beverly, MA, USA). Anti-actin antibody was obtained from Sigma-Aldrich (St. Louis, MO, USA). Other reagents were purchased from Sigma Chemical Co. (St. Louis, MO, USA).

Flow cytometric analysis. For flow cytometry, the cells were resuspended in $100 \mu \mathrm{l}$ of phosphate-buffered saline (PBS), and $200 \mu 1$ of $95 \%$ ethanol was added while the cells were being vortexed. Then, the cells were incubated at $4^{\circ} \mathrm{C}$ for $1 \mathrm{~h}$, washed with PBS, resuspended in $250 \mu \mathrm{l}$ of $1.12 \%$ sodium citrate buffer ( $\mathrm{pH} 8.4$ ) with $12.5 \mu \mathrm{g}$ of RNase and incubated for an additional $30 \mathrm{~min}$ at $37^{\circ} \mathrm{C}$. The cellular DNA was then stained by adding $250 \mu \mathrm{l}$ of a propidium iodide solution $(50 \mu \mathrm{g} / \mathrm{ml})$ to the cells for $30 \mathrm{~min}$ at room temperature. The stained cells were analyzed by fluorescent-activated cell sorting on a FACScan flow cytometer to determine the relative DNA content, which was based on the red fluorescence intensity.

Western blot analysis. Cells were washed with cold PBS and lysed on ice in $50 \mu \mathrm{l}$ of lysis buffer $(50 \mathrm{mM}$ Tris- $\mathrm{HCl}$, $1 \mathrm{mM}$ EGTA, $1 \%$ Triton X-100, $1 \mathrm{mM}$ phenylmethylsulfonyl fluoride, $\mathrm{pH}$ 7.5). Lysates were centrifuged at $10,000 \mathrm{x} \mathrm{g}$ for $15 \mathrm{~min}$ at $4^{\circ} \mathrm{C}$, and the supernatant fractions were collected. Proteins were separated by SDS-PAGE and transferred to an Immobilon-P membrane (Millipore Corp., Bedford, MA, USA). Specific proteins were detected using an enhanced chemiluminescence (ECL) western blot kit (Millipore Corp.) according to the manufacturer's instructions $(15,16)$.

4',6'-Diamidino-2-phenylindole (DAPI) staining for nuclei condensation and fragmentation. To examine cellular nuclei, the cells were fixed with $1 \%$ paraformaldehyde on glass slides for $30 \mathrm{~min}$ at room temperature. After fixation, the cells were washed with PBS and a $300 \mathrm{nM}$ 4',6'-diamidino-2-phenylindole solution (Roche, Mannheim, Germany) was added to the fixed cells for $5 \mathrm{~min}$. After the nuclei were stained, the cells were examined by fluorescence microscopy.

Cell death assessment by DNA fragmentation assay. The cell death detection ELISA Plus kit (Boehringer, Mannheim, Germany) was used for assessing apoptotic activity by detecting fragmented DNA within the nucleus in the cells treated with osthole and TRAIL alone, or the combination of osthole and TRAIL. Briefly, each culture plate was centrifuged for $10 \mathrm{~min}$ at $200 \mathrm{x} \mathrm{g}$, the supernatant was removed, and the pellet was lysed for $30 \mathrm{~min}$. After centrifuging the plate again at $200 \mathrm{x} \mathrm{g}$ for $10 \mathrm{~min}$, the supernatant that contained the cytoplasmic histone-associated DNA fragments was collected and incubated with an immobilized anti-histone antibody. The reaction products were incubated with a peroxidase substrate for $5 \mathrm{~min}$ and measured by spectrophotometry at 405 and $490 \mathrm{~nm}$ (reference wavelength) with a microplate reader. The signals in the wells containing the substrate alone were subtracted as the background.

Asp-Glu-Val-Asp-ase (DEVDase) activity assay. To evaluate DEVDase activity, cell lysates were prepared after their respective treatments with TRAIL in the presence or absence of osthole. Assays were performed in 96-well microtiter plates by incubating $20 \mu \mathrm{g}$ of cell lysates in $100 \mu \mathrm{l}$ of reaction buffer (1\% NP-40, 20 mM Tris-HCl, pH 7.5, 137 mM NaCl, 10\% glycerol) containing a caspase substrate [Asp-Glu-Val-Aspchromophore-p-nitroanilide (DVAD-pNA)] at $5 \mu \mathrm{M}$. Lysates were incubated at $37^{\circ} \mathrm{C}$ for $2 \mathrm{~h}$. Thereafter, the absorbance at $405 \mathrm{~nm}$ was measured with a spectrophotometer.

Determination of the mitochondrial membrane potential by Rhodamine 123. Rhodamine 123 (Molecular Probes Inc., Eugene, OR, USA) uptake by mitochondria is directly proportional to its membrane potential. After treatment, the cells were incubated with Rhodamine $123(5 \mu \mathrm{M})$ for $5 \mathrm{~min}$ in the dark at $37^{\circ} \mathrm{C}$. The cells were harvested and suspended in PBS. The mitochondrial membrane potential (MMP) was subsequently analyzed using a flow cytometer (Becton-Dickinson, Franklin Lakes, NJ, USA).

Analysis of cytochrome c release. The cells were harvested, washed once with ice-cold PBS and gently lysed for $2 \mathrm{~min}$ in $80 \mu \mathrm{l}$ ice-cold lysis buffer [250 mM sucrose, $1 \mathrm{mM}$ EDTA, $20 \mathrm{mM}$ Tris- $\mathrm{HCl}$ (pH 7.2), $1 \mathrm{mM}$ DTT, $10 \mathrm{mM} \mathrm{KCl}, 1.5 \mathrm{mM}$ $\mathrm{MgCl}_{2}, 5 \mu \mathrm{g} / \mathrm{ml}$ pepstatin A, $10 \mu \mathrm{g} / \mathrm{ml}$ leupeptin and $2 \mu \mathrm{g} / \mathrm{ml}$ aprotinin]. Lysates were centrifuged at $12,000 \mathrm{x} \mathrm{g}$ at $4^{\circ} \mathrm{C}$ for $10 \mathrm{~min}$ to obtain the supernatants (cytosolic extracts free of mitochondria) and the pellets (fraction that contains mitochondria). The resulting cytosolic fractions were used for western blot analysis with an anti-cytochrome $c$ antibody.

c-FLIP constructs and stable cell. The human c-FLIP expression vector was constructed as previously described (17). The Caki cells were transfected in a stable manner with the pcDNA 3.1-c-FLIP(L) plasmid using Lipofectamine as prescribed by the manufacturer (Invitrogen, Carlsbad, CA, USA). After $48 \mathrm{~h}$ of incubation, the transfected cells were selected in cell culture medium containing $700 \mu \mathrm{g} / \mathrm{ml} \mathrm{G} 418$ (Invitrogen). After two or three weeks, single independent clones were randomly isolated, and each individual clone was plated separately. After clonal expansion, cells from each independent clone were tested for c-FLIP expression by immunoblotting and were used in the present study.

Statistical analysis. The data were analyzed using a one-way ANOVA and post hoc comparisons (Student-Newman-Keuls) using the Statistical Package for Social Sciences 22.0 software (SPSS, Inc., Chicago, IL, USA). Statistical significance was determined at $\mathrm{P} \leq 0.05$.

\section{Results}

Effect of osthole on TRAIL-mediated apoptosis in human renal carcinoma Caki cells. We investigated whether osthole 
A
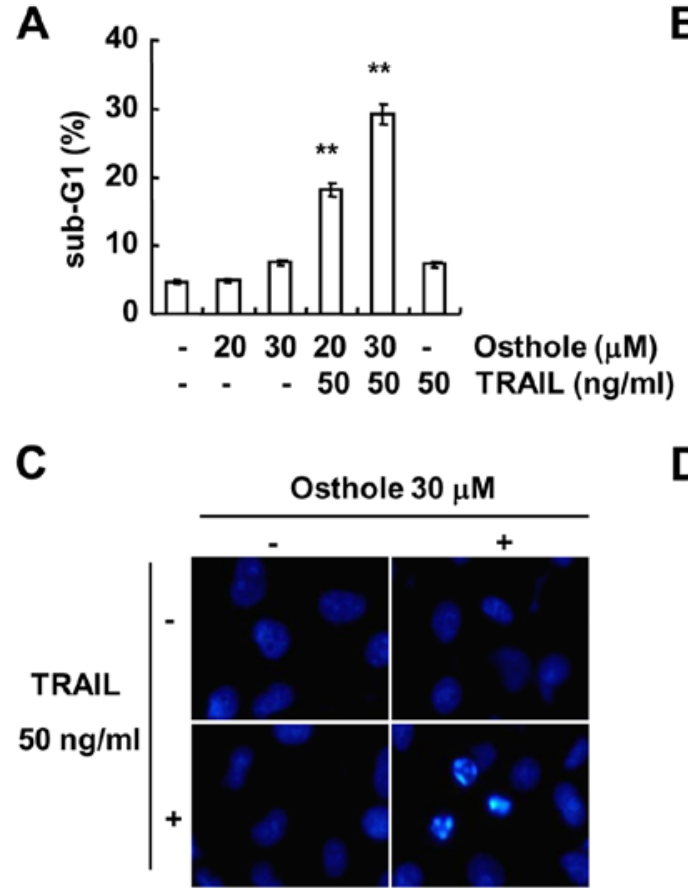

B

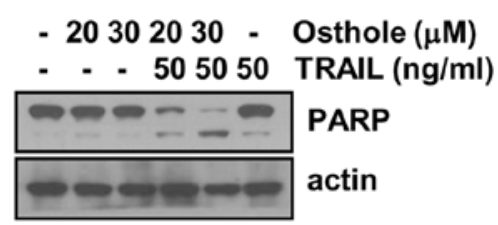

D

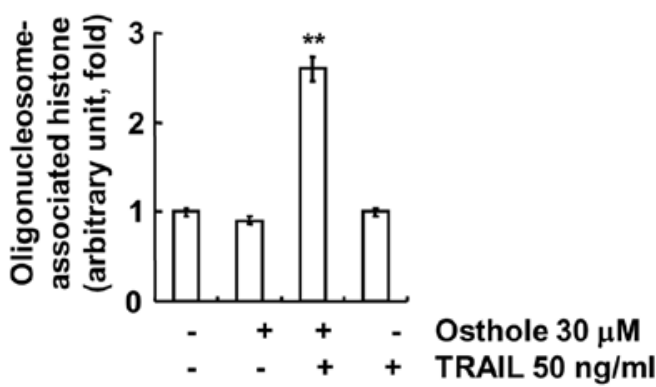

Figure 1. Osthole sensitizes TRAIL-induced apoptosis in Caki cells. (A and B) Caki cells were treated with $50 \mathrm{ng} / \mathrm{ml}$ TRAIL in the presence or absence of the indicated concentrations of osthole for $24 \mathrm{~h}$. (A) Apoptosis was analyzed as a sub-G1 population by flow cytometry. (B) The protein levels of PARP and actin were determined by western blotting. The level of actin was used as a loading control. (C and D) Caki cells were treated with 50 ng/ml TRAIL in the presence or absence of $30 \mu \mathrm{M}$ osthole for $24 \mathrm{~h}$. (C) The condensation and fragmentation of the nuclei were detected by 4',6'-diamidino-2-phenylindole staining. (D) The DNA fragmentation detection kit determined fragmented DNA. The values in A and D represent the mean \pm SD from three independent samples; ${ }^{* *}$ p $<0.01$ compared to the control.

could sensitize TRAIL-mediated apoptosis in human renal carcinoma Caki cells. Cells were treated with osthole alone (20 and $30 \mu \mathrm{M})$, TRAIL alone $(50 \mathrm{ng} / \mathrm{ml})$, and combined treatment with osthole and TRAIL. Apoptosis was determined using flow cytometric and western blot analyses. As shown in Fig. 1A and B, combined treatment with osthole and TRAIL markedly induced accumulation of the sub-G1 population and cleavage of poly(ADP-ribose) polymerase (PARP). However, treatment with osthole and TRAIL alone had no effect on apoptosis. Next, we analyzed nuclear condensation and deoxyribonucleic acid (DNA) fragmentation, which is a hallmark of apoptosis. Osthole plus TRAIL induced nuclear condensation and DNA fragmentation (Fig. 1C and D).

Effect of caspase activation on osthole plus TRAIL-induced apoptosis. Next, we examined whether caspase activation plays a critical role in osthole plus TRAIL-induced apoptosis. Combined treatment with osthole and TRAIL increased caspase-3 activity (Fig. 2A). To confirm the roles of caspase activation in the osthole plus TRAIL-induced apoptosis, a test was conducted to determine whether caspase inhibitors could attenuate apoptosis. Th sub-G1 population and cleavage of PARP and caspase- 3 were completely prevented by pre-treatment with the pan-caspase inhibitor, z-VAD-fmk (Fig. 2B). In addition, we examined whether the loss of MMP is involved in osthole plus TRAIL-induced apoptosis, using Rhodamine 123 fluorescence dye. As shown in Fig. 2C, osthole markedly reduced MMP levels, and increased cytosolic cytochrome $c$ release following the combined treatment with osthole and TRAIL (Fig. 2D).
These results suggest that combined treatment with osthole and TRAIL induced apoptosis in Caki cells through a caspase-dependent pathway.

Effect of combined treatment with osthole and TRAIL on expression of apoptosis-related proteins. To identify the involvement of apoptosis-related proteins in the combined treatment-induced apoptosis in Caki cells, the expression patterns of anti-apoptotic and pro-apoptotic proteins were investigated. Combined treatment markedly induced downregulation of c-FLIP expression, whereas expression of apoptosis-related proteins (DR5, cIAP1, XIAP, Mcl-1 and Bcl-2) did not change (Fig. 3A). To investigate the role of the downregulation of c-FLIP protein in osthole plus TRAIL-induced apoptosis, we used c-FLIP-overexpressing cells. Combined treatment with osthole and TRAIL induced apoptosis in Caki/vector cells, while the sub-G1 population and PARP cleavage were markedly blocked in the ectopic c-FLIP-expressing cells (Fig. 3B). These data suggest that the downregulation of c-FLIP expression plays a critical role in the combined treatment with osthole and TRAIL-induced apoptosis.

Effect of ER stress and ROS signaling pathway on ostholemediated TRAIL sensitization. Next, we investigated whether osthole induces endoplasmic reticulum (ER) stress. As shown in Fig. 4A, protein levels of the $78 \mathrm{kDa}$ glucose-regulated protein (Grp78) increased by osthole in a dose-dependent manner. However, protein levels of activating transcription factor 4 (ATF4) and CCAAT-enhancer-binding protein 
A
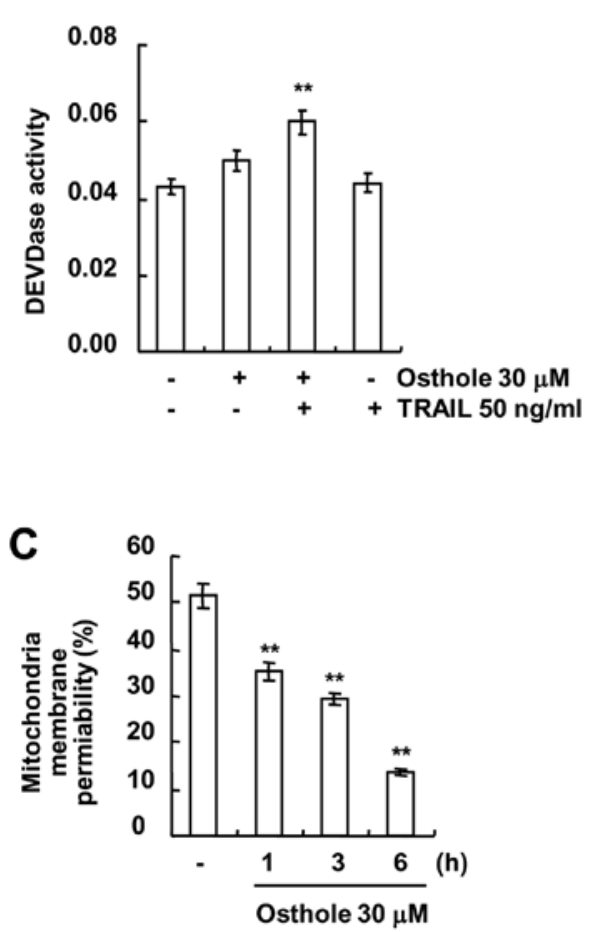

B

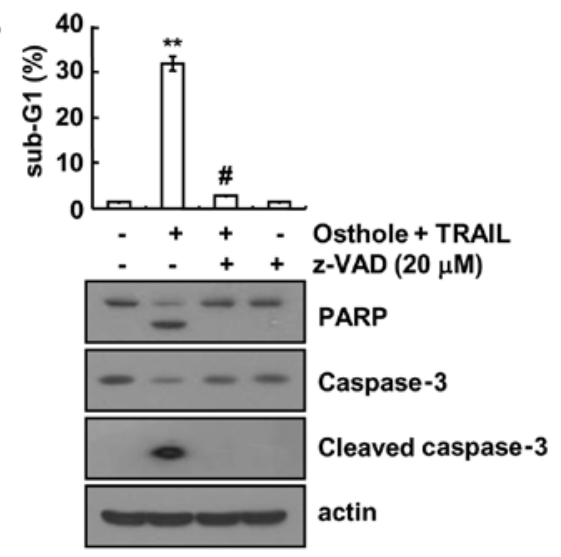

D

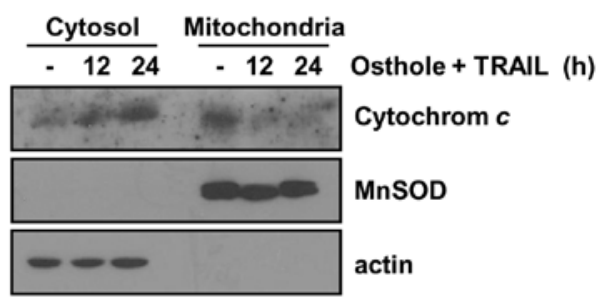

Figure 2. Osthole induces loss of mitochondrial membrane potential (MMP). (A) Caki cells were treated with $50 \mathrm{ng} / \mathrm{ml}$ TRAIL in the presence or absence of $30 \mu \mathrm{M}$ osthole for $24 \mathrm{~h}$. Caspase activities were determined with colorimetric assays using caspase-3 DEVDase assay kits. (B) Caki cells were treated with $30 \mu \mathrm{M}$ osthole plus $50 \mathrm{ng} / \mathrm{ml}$ TRAIL for $24 \mathrm{~h}$ in the presence or absence of $20 \mu \mathrm{M} \mathrm{z}$-VAD-fmk (z-VAD). The sub-G1 fraction was measured by flow cytometry. The protein expression levels of PARP, caspase-3, cleaved caspase- 3 and actin were determined using western blotting. The level of actin was used as a loading control. (C) Caki cells were treated with $30 \mu \mathrm{M}$ osthole for the indicated time periods and loaded with a Rhodamine 123 fluorescent dye. The mitochondrial membrane potential (MMP) was measured using a flow cytometer. (D) Caki cells were treated with $30 \mu \mathrm{M}$ osthole for the indicated time periods. Cytoplasmic fractions were analyzed for cytochrome $c$ release. The level of MnSOD was used as a mitochondrial loading control. The level of actin was used as a loading control. The values in A-C represent the mean \pm SD from three independent samples; ${ }^{* *} \mathrm{p}<0.05$ compared to the control, ${ }^{\sharp} \mathrm{p}<0.01$ compared to the osthole plus TRAIL.
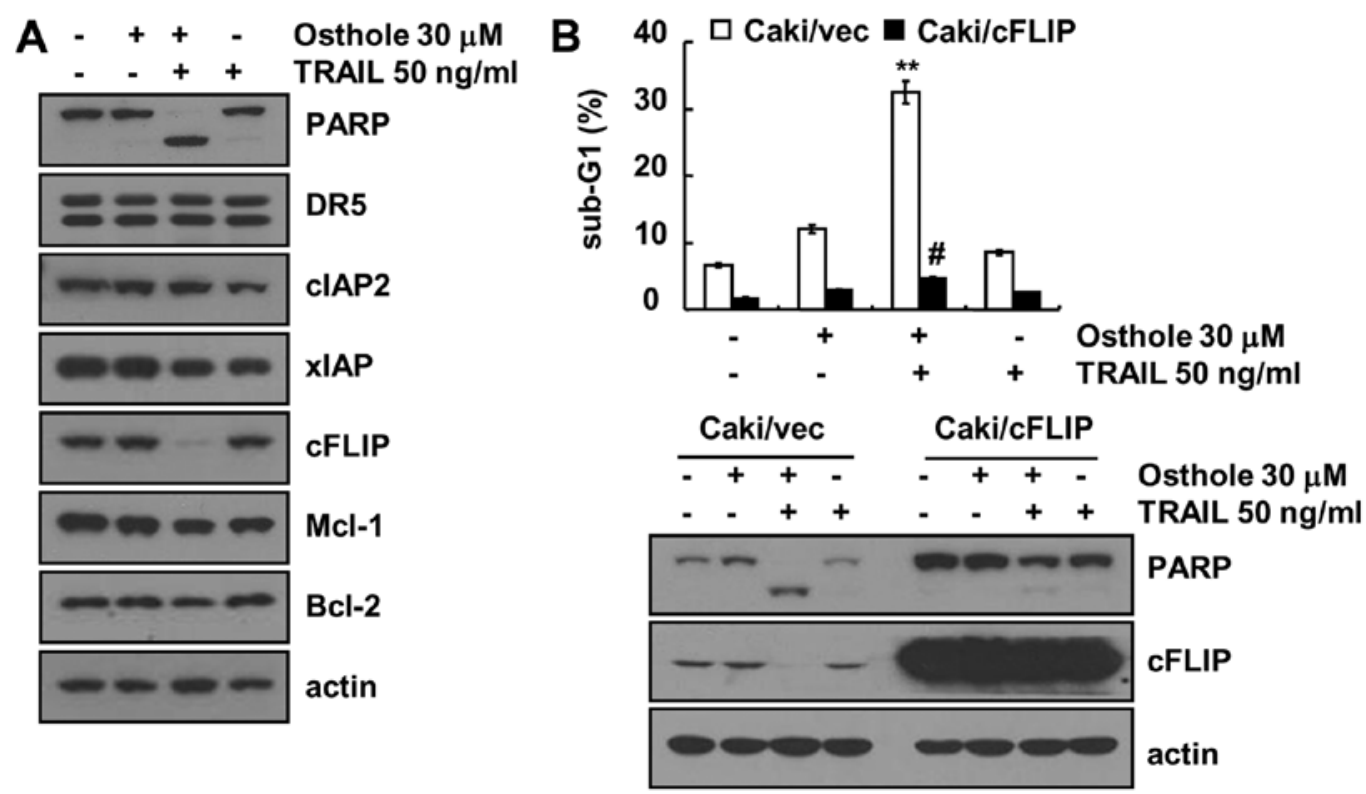

Figure 3. Downregulation of c-FLIP by osthole is associated with the induction of TRAIL-mediated apoptosis. (A) Caki cells were treated with $50 \mathrm{ng} / \mathrm{ml}$ TRAIL in the presence or absence of $30 \mu \mathrm{M}$ osthole for $24 \mathrm{~h}$. The protein expression levels of PARP, DR5, cIAP2, xIAP, c-FLIP, Mcl-1, Bcl-2 and actin were determined using western blotting. The level of actin was used as a loading control. (B) Vector cells (Caki/vector) and c-FLIP-overexpressing cells (Caki/c-FLIP) were treated with $50 \mathrm{ng} / \mathrm{ml}$ TRAIL in the presence or absence of $30 \mu \mathrm{M}$ osthole for $24 \mathrm{~h}$. The sub-G1 fraction was measured by flow cytometry. The protein expression levels of PARP, c-FLIP and actin were determined using western blotting. The level of actin was used as a loading control. The values in $\mathrm{B}$ represent the mean $\pm \mathrm{SD}$ from three independent samples. ${ }^{* *} \mathrm{p}<0.05$ compared to the control Caki/Vec; ${ }^{\#} \mathrm{p}<0.01$ compared to the osthole plus TRAILtreated Caki/Vec cells. 

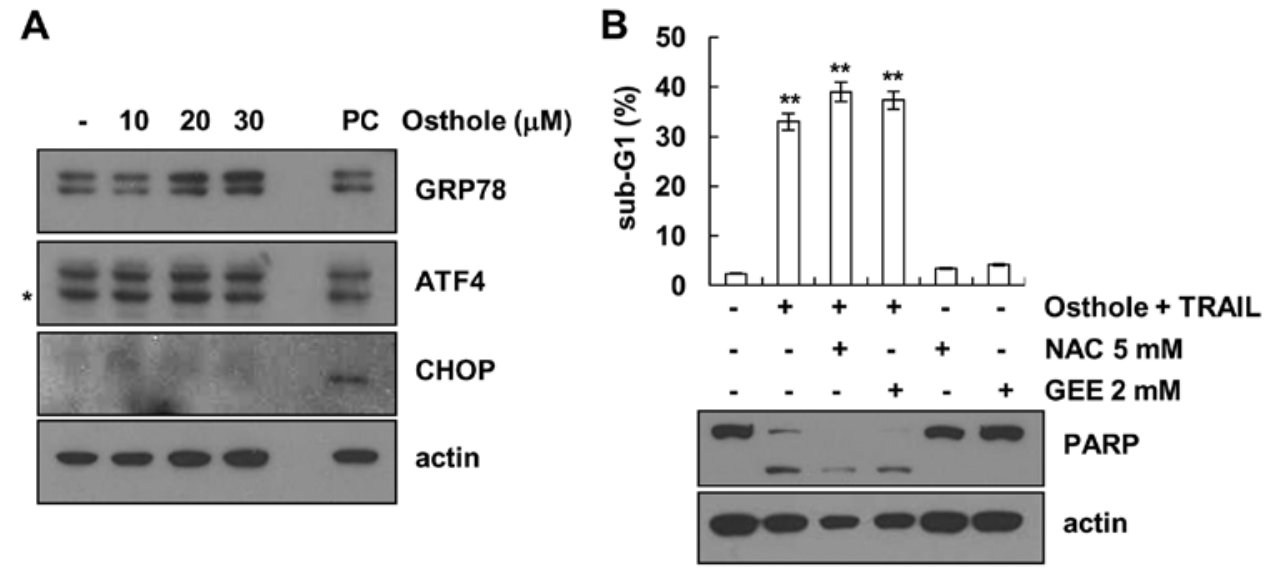

Figure 4. TRAIL sensitization by osthole is independent of ER stress and the ROS signaling pathway. (A) Caki cells were treated with the indicated concentrations of osthole or $2 \mu \mathrm{M}$ brefeldin A (PC; positive control) for $6 \mathrm{~h}$. The protein expression levels of Grp78, ATF4, CHOP and actin were determined using western blotting. The level of actin was used as a loading control. *, non-specific band. (B) Caki cells were pretreated with $5 \mathrm{mM} \mathrm{NAC} \mathrm{and} 2 \mathrm{mM}$ GEE for $30 \mathrm{~min}$, and then $50 \mathrm{ng} / \mathrm{ml}$ TRAIL plus $30 \mu \mathrm{M}$ osthole was added for $24 \mathrm{~h}$. The sub-G1 fraction was measured by flow cytometry. The protein expression levels of PARP and actin were determined by western blotting. The level of actin was used as a loading control. The values in B represent the mean \pm SD from three independent samples. ${ }^{* *} \mathrm{p}<0.05$ compared to the control.

A

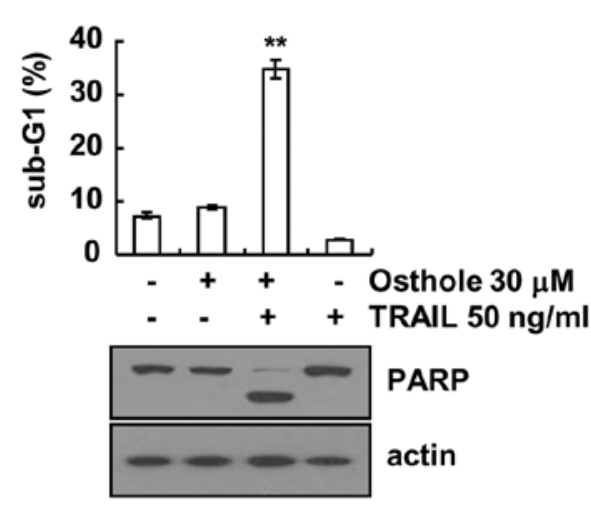

MDA-MB-231

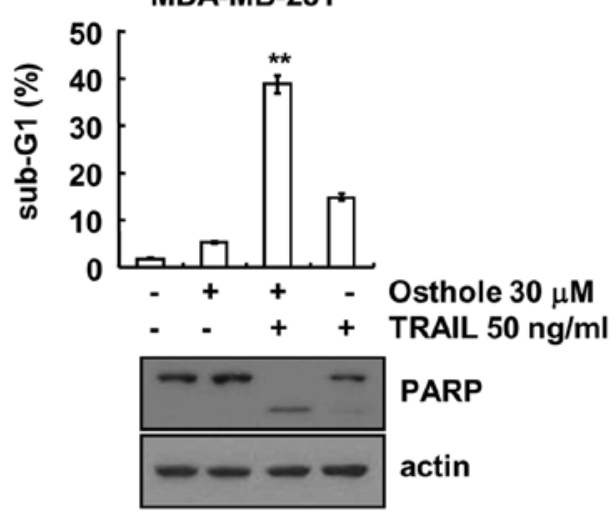

B
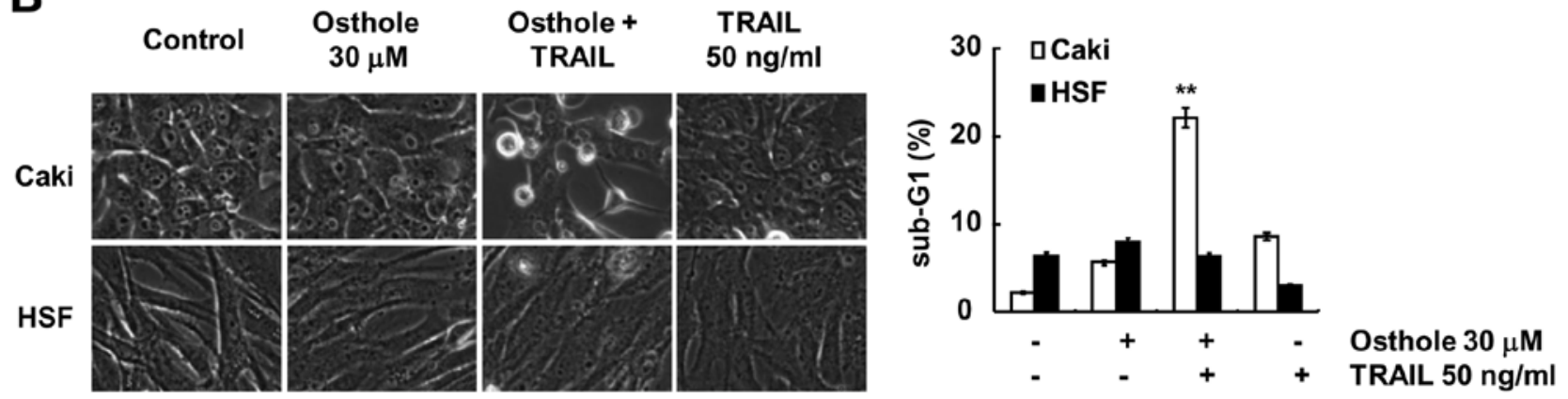

Figure 5. Effects of the combined treatment with osthole and TRAIL on apoptosis in other carcinoma and normal cells. (A) U251MG (glioma) and MDA-MB231 (breast carcinoma) cells were treated with $50 \mathrm{ng} / \mathrm{ml}$ TRAIL in the presence or absence of $30 \mu \mathrm{M}$ osthole for $24 \mathrm{~h}$. The level of apoptosis was measured by the sub-G1 fraction using flow cytometry. The protein expression levels of PARP and actin were determined by western blotting. The level of actin was used as a loading control. (B) Caki and human skin fibroblast (HSF) cells were treated with $50 \mathrm{ng} / \mathrm{ml}$ TRAIL in the presence or absence of $30 \mu \mathrm{M}$ osthole for $24 \mathrm{~h}$. The cell morphology was examined using interference light microscopy. The level of apoptosis was measured by the sub-G1 fraction using flow cytometry. The values in $\mathrm{A}$ and $\mathrm{B}$ represent the mean $\pm \mathrm{SD}$ from three independent samples; ${ }^{* *} \mathrm{p}<0.05$ compared to the control.

homologous protein $(\mathrm{CHOP})$ were not altered in response to osthole. In addition, we investigated whether reactive oxygen species (ROS) is involved in osthole-mediated TRAIL sensitization. As shown in Fig. 4B, ROS scavengers (NAC and GEE) had no effect on osthole plus TRAIL-induced apoptosis. Therefore, osthole-mediated TRAIL sensitization is independent of ER stress and ROS signaling.

Effect of combined treatment with osthole and TRAIL on apoptosis in other cancer and normal cells. Next, we 
investigated whether osthole and TRAIL enhanced apoptosis in other cancer and normal cells. As shown in Fig. 5A, we found that combined treatment with osthole and TRAIL enhanced the sub-G1 population and PARP cleavage in U251MG (glioma) and MDA-MB-231 (breast cancer) cells. In contrast, osthole plus TRAIL had no effect on morphological changes and apoptotic cell death in HSF cells (Fig. 5B). These data indicate that osthole induces TRAIL-mediated apoptosis in cancer cells, but not in normal cells.

\section{Discussion}

In the present study, we showed that osthole promotes TRAIL-mediated apoptotic cell death through downregulation of c-FLIP in human renal carcinoma Caki cells. Furthermore, osthole markedly reduced MMP levels, and increased cytosolic cytochrome $c$ release following combined treatment with osthole and TRAIL. Therefore, these data suggest that osthole could be an effective TRAIL sensitizer.

Recently, Zhang et al reported that osthole significantly inhibited hepatocellular carcinoma growth in vitro and in vivo through cell cycle arrest and induced apoptosis by suppressing $\mathrm{NF}-\kappa \mathrm{B}$ activity and promoting the expression of apoptosis-related genes (18). They used high concentrations $\left(\mathrm{IC}_{50},>100 \mu \mathrm{M}\right)$ of osthole (18). In the present study, a low concentration of osthole $(30 \mu \mathrm{M})$ did not induce apoptotic cell death. However, the combined treatment with osthole $(30 \mu \mathrm{M})$ and TRAIL (50 ng/ml) caused apoptotic cell death in Caki, U251 MG and MDA-MB-231 cells, but not normal cells. Previously several studies have shown that osthole induces apoptotic cell death in many types of cancer cells by various signaling pathways. Osthole induces cell cycle arrest and antitumorigenesis via regulating the PTEN/Akt pathway (19). In addition, osthole significantly induces apoptosis by mitochondrial dysfunction via upregulation of Bax and downregulation of Bcl-2 (20). In the present study, one of the mechanisms of osthole-mediated TRAIL sensitization was found to be downregulation of c-FLIP expression. As shown in Fig. 3B, ectopic expression of c-FLIP markedly blocked apoptosis induced by the combined treatment of osthole and TRAIL. Overexpression of c-FLIP has been observed in multiple types of human cancer, and can protect against cell death receptor-mediated apoptosis through inhibition of caspase- 8 recruitment and death-inducing signaling complex (DISC) formation (21-24).

In the present study, osthole induced Grp78 expression, while CHOP and ATF4 did not change. Upregulation of DR5 and Bim expression by CHOP and ATF4 plays important roles in ER stress-mediated apoptosis (25). However, osthole treatment did not induce upregulation of DR5, CHOP and ATF4. Lv et al reported that osthole prevents tricalcium phosphate particles-induced osteoclastogenesis and osteolysis in vivo through inhibition of the ER stress signaling pathway (26). Therefore, osthole-mediated TRAIL sensitization is independent of ER stress signaling.

Collectively, these findings revealed that osthole sensitized TRAIL-mediated apoptosis through the downregulation of c-FLIP expression in human renal Caki cells. Therefore, osthole may be an attractive sensitizer for TRAIL-resistant cancer cells.

\section{Acknowledgements}

The present study was supported by an NRF grant funded by the Korea Government (MSIP) (2014R1A5A2010008), and a 2016 Scholar Research Grant from Keimyung University.

\section{References}

1. Maas M, Deters AM and Hensel A: Anti-inflammatory activity of Eupatorium perfoliatum L. extracts, eupafolin, and dimeric guaianolide via iNOS inhibitory activity and modulation of inflammation-related cytokines and chemokines. J Ethnopharmacol 137: 371-381, 2011.

2. Chung KS, Choi JH, Back NI, Choi MS, Kang EK, Chung HG, Jeong TS and Lee KT: Eupafolin, a flavonoid isolated from Artemisia princeps, induced apoptosis in human cervical adenocarcinoma HeLa cells. Mol Nutr Food Res 54: 1318-1328, 2010.

3. Liu K, Park C, Chen H, Hwang J, Thimmegowda NR, Bae EY, Lee KW, Kim HG, Liu H, Soung NK, et al: Eupafolin suppresses prostate cancer by targeting phosphatidylinositol 3-kinase-mediated Akt signaling. Mol Carcinog 54: 751-760, 2015.

4. Kim SR, Park MJ, Lee MK, Sung SH, Park EJ, Kim J, Kim SY, Oh TH, Markelonis GJ and Kim YC: Flavonoids of Inula britannica protect cultured cortical cells from necrotic cell death induced by glutamate. Free Radic Biol Med 32: 596-604, 2002.

5. Wen YC, Lee WJ, Tan P, Yang SF, Hsiao M, Lee LM and Chien MH: By inhibiting snail signaling and miR-23a-3p, osthole suppresses the EMT-mediated metastatic ability in prostate cancer. Oncotarget 6: 21120-21136, 2015.

6. Xu XM, Zhang Y, Qu D, Feng XW, Chen Y and Zhao L: Osthole suppresses migration and invasion of A549 human lung cancer cells through inhibition of matrix metalloproteinase- 2 and matrix metallopeptidase-9 in vitro. Mol Med Rep 6: 1018-1022, 2012.

7. Wiley SR, Schooley K, Smolak PJ, Din WS, Huang CP, Nicholl JK, Sutherland GR, Smith TD, Rauch C, Smith CA, et al: Identification and characterization of a new member of the TNF family that induces apoptosis. Immunity 3: 673-682, 1995.

8. Wang S and El-Deiry WS: TRAIL and apoptosis induction by TNF-family death receptors. Oncogene 22: 8628-8633, 2003.

9. Kischkel FC, Lawrence DA, Chuntharapai A, Schow P, Kim KJ and Ashkenazi A: Apo2L/TRAIL-dependent recruitment of endogenous FADD and caspase- 8 to death receptors 4 and 5 . Immunity 12: 611-620, 2000.

10. Walczak H, Bouchon A, Stahl H and Krammer PH: Tumor necrosis factor-related apoptosis-inducing ligand retains its apoptosis-inducing capacity on $\mathrm{Bcl}-2$ - or $\mathrm{Bcl}-\mathrm{x}_{\mathrm{L}}$-overexpressing chemotherapy-resistant tumor cells. Cancer Res 60: 3051-3057, 2000.

11. Kelly MM, Hoel BD and Voelkel-Johnson C: Doxorubicin pretreatment sensitizes prostate cancer cell lines to TRAIL induced apoptosis which correlates with the loss of c-FLIP expression. Cancer Biol Ther 1: 520-527, 2002.

12. Ng CP, Zisman A and Bonavida B: Synergy is achieved by complementation with Apo2L/TRAIL and actinomycin D in Apo2L/TRAIL-mediated apoptosis of prostate cancer cells: Role of XIAP in resistance. Prostate 53: 286-299, 2002.

13. Jin Z, McDonald ER III, Dicker DT and El-Deiry WS: Deficient tumor necrosis factor-related apoptosis-inducing ligand (TRAIL) death receptor transport to the cell surface in human colon cancer cells selected for resistance to TRAIL-induced apoptosis. J Biol Chem 279: 35829-35839, 2004.

14. Zhang Y and Zhang B: TRAIL resistance of breast cancer cells is associated with constitutive endocytosis of death receptors 4 and 5. Mol Cancer Res 6: 1861-1871, 2008.

15. Jo HS, Yeo HJ, Cha HJ, Kim SJ, Cho SB, Park JH, Lee CH, Yeo EJ, Choi YJ, Eum WS, et al: Transduced Tat-DJ-1 protein inhibits cytokines-induced pancreatic RINm5F cell death. BMB Rep 49: 297-302, 2016.

16. Han EH, Kim HG, Lee EJ and Jeong HG: Endosulfan induces CYP1A1 expression mediated through aryl hydrocarbon receptor signal transduction by protein kinase C. Toxicol Res 31: 339-345, 2015.

17. Kim S, Lee TJ, Leem J, Choi KS, Park JW and Kwon TK: Sanguinarine-induced apoptosis: Generation of ROS, down-regulation of Bcl-2, c-FLIP, and synergy with TRAIL. J Cell Biochem 104: 895-907, 2008. 
18. Zhang L, Jiang G, Yao F, He Y, Liang G, Zhang Y, Hu B, Wu Y, $\mathrm{Li} \mathrm{Y}$ and Liu H: Growth inhibition and apoptosis induced by osthole, a natural coumarin, in hepatocellular carcinoma. PLoS One 7: e37865, 2012.

19. Wang L, Yang L, Lu Y, Chen Y, Liu T, Peng Y, Zhou Y, Cao Y, Bi Z, Liu T, et al: Osthole induces cell cycle arrest and inhibits migration and invasion via PTEN/Akt pathways in osteosarcoma. Cell Physiol Biochem 38: 2173-2182, 2016.

20. Ding Y, Lu X, Hu X, Ma J and Ding H: Osthole inhibits proliferation and induces apoptosis in human osteosarcoma cells. Int J Clin Pharmacol Ther 52: 112-117, 2014.

21. Oyarzo MP, Medeiros LJ, Atwell C, Feretzaki M, Leventaki V, Drakos E, Amin HM and Rassidakis GZ: c-FLIP confers resistance to FAS-mediated apoptosis in anaplastic large-cell lymphoma. Blood 107: 2544-2547, 2006.

22. Zhou XD, Yu JP, Liu J, Luo HS, Chen HX and Yu HG: Overexpression of cellular FLICE-inhibitory protein (FLIP) in gastric adenocarcinoma. Clin Sci 106: 397-405, 2004.
23. Ryu BK, Lee MG, Chi SG, Kim YW and Park JH: Increased expression of $\mathrm{CFLIP}_{\mathrm{L}}$ in colonic adenocarcinoma. J Pathol 194: $15-19,2001$

24. Li X, Pan X, Zhang H, Lei D, Liu D, Xu F and Luan X: Overexpression of cFLIP in head and neck squamous cell carcinoma and its clinicopathologic correlations. J Cancer Res Clin Oncol 134: 609-615, 2008.

25. Jung KJ, Min KJ, Bae JH and Kwon TK: Carnosic acid sensitized TRAIL-mediated apoptosis through down-regulation of c-FLIP and Bcl-2 expression at the post translational levels and CHOP-dependent up-regulation of DR5, Bim, and PUMA expression in human carcinoma caki cells. Oncotarget 6: 1556-1568, 2015

26. Lv S, Zhang Y, Yan M, Mao H, Pan C, Gan M, Fan J and Wang G: Inhibition of osteolysis after local administration of osthole in a TCP particles-induced osteolysis model. Int Orthop 40: 1545-1552, 2016. 